\title{
CURSOS DE GESTÃo DE RECURSOS HUMANOS: UMA ANÁLISE
} DOCUMENTAL

\author{
CARRERAS DE GESTIÓN DE RECURSOS HUMANOS: ANÁLISIS \\ DOCUMENTAL \\ COURSES IN HUMAN RESOURCE MANAGEMENT: DOCUMENTARY \\ ANALYSIS
}

http://dx.doi.org/10.1590/1807-03102016v28n2p396

Camila Teixeira Heleno e Livia de Oliveira Borges Universidade Federal de Minas Gerais, Belo Horizonte/MG, Brasil

\section{RESUMO}

Objetivos: (a) identificar marcos históricos e institucionais que norteiam os cursos de Gestão de Recursos Humanos (GRH); (b) analisar Projetos Pedagógicos de Curso (PPCs); (c) identificar o perfil dos docentes. $\mathrm{O}$ referencial teórico é o da perspectiva psicossociológica de vertente institucionalista. Realizou-se pesquisa documental utilizando: (a) deliberações do Conselho Nacional de Educação; (b) leis e decretos federais; (c) PPCs de GRH. Identificaram-se como marcos: (a) caráter assistencialista e moralista; (b) dualidade do sistema educacional; (c) aumento da responsabilização do setor privado; (d) vínculo com desenvolvimento econômico e tecnológico. Conclui-se que o apoio de políticas públicas, a indistinção do perfil profissional e da demanda levam a questionar a fundamentação destes cursos, se advindos das mudanças no mundo do trabalho e/ou da intenção de promover o mercado de ensino superior do país.

Palavras-chave: política científica e tecnológica; ensino superior; trabalho docente.

\section{RESUMEN}

Objetivos: (a) identificar los marcos históricos e institucionales que guían a los cursos de Gestión de Recursos Humanos (GRH); (b) análisis de los Proyectos Pedagógicos de Curso (PPCs); (c) identificar el perfil de los profesores de GRH. El referencial teórico es la perspectiva psicosociológica con vertiente institucionalista. La investigación documental se realizó con: (a) las resoluciones y dictámenes del Consejo Nacional de Educación; (b) las leyes federales y los decretos; (c) PPCs de GRH. Se identificaron como los marcos institucionales: (a) enfoque paternalista y moralizante; (b) la dualidad del sistema educativo; (c) el aumento de la responsabilidad del sector privado; (d) vinculación con el desarrollo económico y tecnológico. En conclusión, el apoyo de las políticas públicas, la indistinción del perfil profesional y la definición de la demanda llevan a cuestionar el fundamento de los cursos de gestión de recursos humanos, si advenidos de los cambios económicos, tecnológicos en el mundo del trabajo y/o la intención de promover el mercado de la educación superior en el país.

Palabras clave: política de ciencia y tecnología; educación superior; trabajo docente.

\begin{abstract}
The aims of this research were to: (a) identify historical and institutional frameworks that guide the courses of Human Resource Management (HRM); (b) analyze the Pedagogical Course Projects (PCPs); (c) identify the teachers' profile. The theoretical framework is the psychosociology perspective with a institutionalist slope. We conducted documentary research from (a) deliberations of the National Council of Education; (b) federal laws; (c) PCPs of HRM. We identified the following as institutional landmarks: (a) assistentialism and moralistic characteristics; (b) duality of the educational system; (c) increasing the responsibility of the private sector; (d) linking with the economic and technological development. The conclusion is that the support of public policies, distinction of the professional profile and demand leads to questioning the existence and maintenance of HRM courses, whether arising from changes in the world of work and/or from the intention to promote the market for undergraduate education in the country.
\end{abstract}

Keywords: scientific policy; undergraduate education; teaching work. 


\section{Introdução}

Há um crescimento dos Cursos Superiores de Tecnologia (CSTs) em todo país (Campello et al., 2009; INEP, 2013). Esses são graduações de nível superior com características especiais, como: (a) natureza e densidade mais tecnológica do que científica; (b) duração menor; (c) resposta a demandas do mercado de trabalho, da sociedade e/ou estudantil, bem como a um perfil profissional específico e atualizado (Parecer CNE/CP n. 29, 2002). Os CSTs devem cumprir funções, como: incentivar a produção, a inovação científico-tecnológica e o empreendedorismo; desenvolver competências para a produção de bens e serviços e gestão de processos; promover a aprendizagem continuada; e garantir a identidade do perfil profissional de conclusão (Resolução $\mathrm{CNE} / \mathrm{CP}$ n. 3, 2002).

O curso de Gestão de Recursos Humanos (GRH) é uma das 112 graduações do Catálogo de CSTs e faz parte do eixo tecnológico de gestão e negócios (MEC, 2010) que "compreende atividades de administração e de suporte logístico à produção e à prestação de serviços" (Resolução CNE/CEB n. 04, 1999, p. 12). As competências específicas dos cursos dependem do perfil profissional de conclusão definido nos Projetos Pedagógicos de Curso (PPCs) (Resolução CNE/ CEB n. 04, 1999), pelos Estabelecimentos de Ensino Superior (EES). Em abril de 2015 existiam 4.604 cursos em atividade no país, sendo 1.128 presenciais (http://emec.mec.gov.br).

A construção de um projeto político-educacional para um país supõe, entre outros aspectos, uma opção ideológica e a constituição da educação como instrumento excepcional de controle social (Rosas, 1992). Isso é coerente com as frequentes investidas para refuncionalizar a educação profissional (EP) que representa a consolidação das relações entre a esfera produtiva e a educação escolar (Duch \& Laudares, 2009). O crescimento econômico está diretamente correlacionado ao nível educacional dos membros de uma sociedade (Freitag, 1977), o que influencia as condições de expansão das instituições públicas e privadas e a elevação do nível da EP (até pósgraduação) (Laudares \& Tomasi, 2003).

$\mathrm{O}$ ensino superior compartilha, também, aspectos relacionados à seletividade social, ao controle do tipo/nível de formação, do fomento e da qualidade da educação (Azevedo et al., 1932/2006; Bayma, 2012; Campello et al., 2009) e à discussão da tendência de aumento de qualificação. Discute-se seu relacionamento a fatores, como: desenvolvimento tecnológico, competitividade, massificação da educação, desvalorização dos títulos escolares, empresariamento do ensino superior (Azevedo, 2011; Takahashi \& Amorim, 2008) e influências internacionais como da declaração de Bolonha de 1999, que fomenta cursos com pequenos custos e duração e dissemina a precarização do trabalho docente (Bianchetti, 2010).

Existem, ainda, aspectos relacionados à desvalorização histórica do tecnólogo e sua configuração de ensino relegado às classes menos favorecidas (Peterossi, 1980). A negação parcial dos direitos sociais, visto que a educação é também prérequisito para a expansão dos direitos civis e políticos, confronta a ideia de justiça social que permite a redução da desigualdade produzida pelo capitalismo (Carvalho, 2007).

Neste contexto que contrapõe o crescimento atual dos CSTs e desvalorização histórica do tecnólogo, planejamos a presente pesquisa e dois de seus objetivos, quais sejam: (a) identificar marcos históricos e institucionais que norteiam os cursos de GRH no país; e (b) analisar a incorporação das determinações legais nos PPCs.

Ademais, consideramos que a Psicologia no Brasil atentou à educação profissional em alguns momentos, como: os trabalhos psicotécnicos de Roberto Mange no Liceu de Artes e Ofícios de São Paulo, em 1924 (Bosi, 1994) e outros trabalhos no início dos serviços nacionais de aprendizagem (Zanelli, Bastos, \& Rodrigues, 2014). Mas sobre os docentes dos CSTs foram encontrados poucos estudos, os quais focalizam prioritariamente a sua formação (e. g., Costa, 2012) e nenhum trata dos docentes do curso de GRH.

Burnier et al. (2007), por exemplo, encontraram que a maioria dos docentes de sua amostra é oriunda de famílias da classe trabalhadora sem trajetória acadêmica e tem a docência como alternativa à sua profissão de origem. Shiroma e Lima (2011) discutiram a precariedade das condições contratuais, institucionais e de trabalho e falta de concursos públicos específicos para essa modalidade.

A constatação dessa lacuna de conhecimento e os achados específicos, revelando aspectos pontuais da singularidade desses docentes, motivaram-nos a planejar o terceiro objetivo da presente pesquisa: (c) identificar o perfil dos docentes dos cursos de GRH. Corroborando a importância de estudar aspectos da identidade ocupacional, Carreteiro e Barros (2011) argumentaram que as atividades profissionais atingem diferencialmente os sujeitos, variando de acordo com 
as competências, o nível de formação e a condição social.

Esperamos que a consecução dos três objetivos citados nos apoie para propor uma agenda de pesquisa contextualizada para a Psicologia do Trabalho e das Organizações (PTO), sensibilizando o interesse pelo assunto e contribuindo para construir uma linha de pesquisa.

\section{As perspectivas psicossociológicas}

A psicossociologia compartilha tendências contemporâneas da PTO, como o reconhecimento da natureza dinâmica, processual, multicausal e multidimensional dos fenômenos, a articulação de diferentes níveis de análise - individual, interpessoal, organizacional e societal -, que se interpenetram (Katzell, 1994; Munduate, 1997). Em sua vertente institucionalista, prioriza o estudo de fenômenos coletivos (Peres, 2008). "Uma instituição é um sistema lógico de definições de uma realidade social e de comportamentos humanos aos quais classifica e divide, atribuindo-lhes valores e decisões" (Baremblitt, 1994, pp. 87-88). Dessa forma, compreende-se que essa perspectiva de análise se aplica à consecução dos objetivos, haja vista que a história e consolidação dos cursos de GRH é processo social amplo que envolve vários atores coletivos, como: Estado; EES; tecnólogos; docentes; e organizações (mercado empregador destes tecnólogos). As instituições, no caso o sistema educacional brasileiro, medeiam as relações de interferência mútua entre estruturas sociais e os comportamentos dos atores sociais e seu estudo pode contribuir para compreender a ação dos indivíduos e as manifestações coletivas (Therét, 2003).

Essa vertente agrega esforços para analisar o tecido social, sua dinâmica política e os atravessamentos da estrutura institucional (Baremblitt, 1994). Essas análises são ferramentas para compreender as mudanças nas metas e ideologias do mundo sociopolítico, em uma concepção histórica que considera as relações de poder (Hall \& Taylor, 2003).

Essa perspectiva considera os sujeitos ativos e busca a aproximação da realidade pela contextualização sócio-histórica, articulada à análise da vida cotidiana e da percepção individual, permitindo acesso aos significados e às experiências, individuais e compartilhadas (Borges, Guimarães, \& Silva, 2013; Carreteiro \& Barros, 2011). Esta perspectiva somada à noção de que a compreensão integral do ser humano necessariamente inclui sua inserção no mundo do trabalho (Zanelli, Bastos, \&
Rodrigues, 2014) constituem os pressupostos teóricos básicos adotados.

\section{Estratégias metodológicas}

Desenvolveu-se pesquisa documental, que se caracteriza por partir de uma fonte natural de informações, fornecendo dados sobre um determinado contexto histórico, econômico e social (Godoy, 1995). Adotaram-se três fontes: (a) resoluções e pareceres do Conselho Nacional de Educação (CNE) e de suas comissões (Conselho Pleno [CP], Câmara de Educação Básica [CEB], Câmara de Educação Superior [CES]); (b) leis e decretos federais; e (c) 24 PPCs de GRH do país.

Identificaram-se as resoluções e pareceres do CNE no portal do MEC (http://portal.mec.gov.br), compreendendo desde o início de registro (1996) até maio de 2013. Selecionaram-se os documentos por contribuírem para a compreensão dos CSTs e do papel desses no sistema de ensino nacional. Selecionaramse as leis e decretos federais que retratam os marcos institucionais da GRH na sociedade brasileira, a partir das resoluções e pareceres do CNE, do texto das próprias leis e decretos e na literatura consultada.

Os PPCs foram obtidos por meio de sites de busca e adotou-se como critério de saturação a não ocorrência seguida em 50 vezes após busca conjunta pelas expressões: "projeto pedagógico" "gestão de recursos humanos". Os PPCs refletem os pressupostos orientadores dos cursos na dimensão global (organização do Estado e da sociedade), específica (políticas educacionais) e particular (elementos históricos e sociais dos cursos e dos EES) (Coelho-Lima, 2013). Nos PPCs, analisaramse: histórico e justificativa do curso; indicadores de demanda; descrições sobre docentes como quantidade, formação e titulação. Aplicou-se análise de conteúdo hermenêutico-dialética (Minayo, 2006).

\section{Resultados e discussão}

Os cursos de GRH no Brasil surgiram no contexto da EP. Essa, por sua vez, tem uma história sobre a qual os documentos analisados permitiram a identificação de seis fases (Tabela 1): $1^{a}$ fase: início no país (Monarquia); $2^{a}$ fase: início da Rede (início da República até a década de 1930); $3^{a}$ fase: ampliação no nível médio (até final da década de 1960); $4^{a}$ fase: graduação intermediária (até a Nova Constituição); $5^{\text {a }}$ fase: tecnológica-economicista (até início século XXI); $6^{\mathrm{a}}$ fase: tecnológicaeconomicista com democratização (atual). 


\section{Tabela 1. Fases da história da educação profissional no Brasil}

\begin{tabular}{cc}
\hline Descrição & Documentos \\
\hline $1^{\text {a }}$ Fase: início no país (Monarquia)
\end{tabular}

Iniciou em 1808, com intuito Alvará do Império de afastar os vassalos do ócio. $\quad(01 / 04 / 1808)$;

Tinha caráter assistencialista Decreto do Império e moralista. Instalou o (23/03/1809);

Collegio das Fábricas e os Parecer CNE/

Liceus de Artes e Ofícios. $\quad$ CP n ${ }^{\circ}$ 29/2002.

\begin{tabular}{|c|c|}
\hline \multicolumn{2}{|c|}{$\begin{array}{l}2^{a} \text { Fase: início da Rede (na República até } \\
\text { aproximadamente década de 1930) }\end{array}$} \\
\hline $\begin{array}{l}\text { Iniciou em 1906, com } \\
\text { institucionalização da rede } \\
\text { de ensino profissionalizante. } \\
\text { Criaram-se escolas de } \\
\text { aprendizes artífices para } \\
\text { filhos dos desfavorecidos da } \\
\text { fortuna. Dever do governo } \\
\text { formar cidadãos úteis. }\end{array}$ & $\begin{array}{l}\text { Decretos da República: } \\
\mathrm{n}^{\circ} 1.606(1906) ; \mathrm{n}^{\circ} 7.566 \\
(1909) . \\
\text { Parecer CNE/CEB n } \\
\text { 16/1999. }\end{array}$ \\
\hline
\end{tabular}

\begin{tabular}{|c|c|}
\hline \multicolumn{2}{|c|}{$\begin{array}{c}3^{\text {a }} \text { Fase: ampliação no nível médio (até final da } \\
\text { década de 1960) }\end{array}$} \\
\hline $\begin{array}{l}\text { Iniciou em 1927, com a } \\
\text { instituição da obrigatorie- } \\
\text { dade do ensino profissional } \\
\text { nas escolas primárias e se- } \\
\text { cundárias subvencionadas } \\
\text { pela União. Previu ensino } \\
\text { pré-vocacional profissional } \\
\text { para as classes menos favo- } \\
\text { recidas. Iniciou serviços na- } \\
\text { cionais de aprendizagem e o } \\
\text { processo gradual de equipa- } \\
\text { ração entre cursos médios e } \\
\text { técnicos. Criaram-se cursos } \\
\text { superiores experimentais na } \\
\text { área de engenharia. }\end{array}$ & $\begin{array}{l}\text { Decretos da República: } \\
\mathrm{n}^{\circ} 5.241(1927) ; \mathrm{n}^{\circ} 8.673 \\
(1942) ; \mathrm{n}^{\circ} 4.127(1942) ; \mathrm{n}^{\circ} \\
34.330(1953) . \\
\text { Leis da República: } \mathrm{n}^{\circ} 1.076 \\
(1950) ; \mathrm{n}^{\circ} 1.821(1953) ; \mathrm{n}^{\circ} \\
\text { 4.024 (1961). Brasil, } 1937 . \\
\text { Pareceres: CNE/CEB } \\
\mathrm{n}^{\circ} 16 / 1999 ; \mathrm{CNE} / \mathrm{CP}^{\circ}{ }^{\mathrm{o}} \\
\text { 29/2002. }\end{array}$ \\
\hline
\end{tabular}

\begin{tabular}{l}
\hline \multicolumn{3}{c}{ 4 $^{\text {a }}$ Fase: graduação intermediária (até a Nova } \\
Constituição)
\end{tabular}

\section{$5^{\mathrm{a}}$ Fase tecnológica-economicista (até início século XXI)} popular na vida pública, o discurso de redução das desigualdades sociais, integração social dos setores desfavorecidos e superação do assistencialismo. Incrementou a parceria entre setor privado e governo na gestão e no financiamento. Proibiu-se a expansão da oferta de educação profissional no âmbito federal. Introduziu o termo tecnológico e focalizaram-se flexibilidade, interdisciplinaridade, atualização permanente e contextualização dos cursos. Ampliaram-se o campo e as exigências para docentes. Instituiu-se o Sistema Nacional de Educação Tecnológica.
Ampliou-se a participação
Brasil, 1988; Decretos

Federais: $n^{\circ} 2.208$ (1997); $\mathrm{n}^{\circ} 2.406$ (1997); $\mathrm{n}^{\circ} 3.860$ (2001). Leis Federais: $n^{\circ}$ 8.436 (1992); n 8.948 (1994); $n^{\circ} 9.131$ (1995); $\mathrm{n}^{\circ} 9.288$ (1996); $\mathrm{n}^{\circ} 9.394$ (1996); $n^{\circ} 9.649$ (1998); $n^{\circ}$ 10.172 (2001). MP n ${ }^{\circ} 1.827$ (1999).

Pareceres: CNE/CEB n ${ }^{\circ}$ 17/1997;

CNE/CEB n ${ }^{\circ}$ 16/1999; $\mathrm{CNE} / \mathrm{CES} n^{\circ} 436 / 2001$; $\mathrm{CNE} / \mathrm{CP}^{\circ}{ }^{\circ} 29 / 2002$; CNE/CEB n ${ }^{\circ}$ 40/2004; $\mathrm{CNE} / \mathrm{CES} n^{\circ}$ 277/2006; CNE/CES n ${ }^{\circ} 19 / 2008$.

\section{$6^{\mathrm{a}}$ Fase: tecnológica-economicista com democratização (atual)}

Modificou-se a legislação, Decretos Federais: $\mathrm{n}^{\circ} 5.154$ expansão da rede federal, $\mathrm{n}^{\mathrm{o}} 6.095$ (2007); $\mathrm{n}^{\circ} 6.096$ conforme a reorientação (2007); $\mathrm{n}^{\circ} 6.301$ (2007); das políticas federais. $\mathrm{n}^{\circ} 6.302(2007) ; \mathrm{n}^{\circ} 6.303$ Implementaram-se políticas (2007); $\mathrm{n}^{\circ} 7.234(2010)$; para a educação nacional $\mathrm{n}^{0} 7.589(2011) ; \mathrm{n}^{\circ} 7.824$ que consideram a dimensão (2012). da inclusão social e as práticas compensatórias. Estreitamento das fronteiras entre as áreas de atuação por conta da velocidade de mudanças nas exigências aos profissionais no mundo da produção, serviços e trabalho. Surgimento do curso de GRH e outras graduações tecnológicas. em 2005, permitindo a (2004); $\mathrm{n}^{\circ} 5.840$ (2006);
Leis Federais: $\mathrm{n}^{\mathrm{o}} 11.096$ (2005); $\mathrm{n}^{\circ} 11.180$ (2005); $\mathrm{n}^{\mathrm{o}} 11.195$ (2005); $\mathrm{n}^{\mathrm{o}} 11.692$ (2008); $\mathrm{n}^{\circ} 11.892$ (2008); $\mathrm{n}^{\mathrm{o}}$ 12.711 (2012)

\section{Pareceres: CNE ${ }^{\circ}$} 776/1997; CNE/CEB $n^{\circ} 16 / 1999 ; \mathrm{CNE} / \mathrm{CP}^{\circ}{ }^{\circ}$ 29/2002; $\mathrm{CNE} / \mathrm{CP}^{\circ}{ }^{\circ}$ 6/2006. Resolução CNE/CP $n^{\circ} 3 / 2002$.
A identificação dos marcos institucionais, por meio da análise dos documentos, permitiu o levantamento de aspectos que foram se consolidando nessas fases como tendências: (a) o caráter assistencialista e moralista; (b) a dualidade do sistema educacional; (c) a crescente responsabilização do setor privado; e (d) o vínculo com o desenvolvimento econômico e tecnológico. 
O caráter assistencialista e moralista contribuiu à desvalorização do tecnólogo. É evidenciado nos documentos desde o século XIX, quando a EP surge como ensino destinado a promover a riqueza nacional e afastar os "vassalos" do "vício da ociosidade" (Alvará de 01/04/1808). Segue, ao longo dos anos, como educação para as classes menos favorecidas até as transformações no final do século XX com elevação ao nível superior e defesa da formação continuada para um profissional inovador. Ainda que se modificaram as estratégias nos documentos, com abolição de palavras com conotação negativa, como "vassalos" ou "desfavorecidos" (Decreto n. 7.566, 23/09/1909), persiste a desvalorização do tecnólogo que nega a institucionalização da ocupação de docente da EP. Não só pelo registro no decreto, mas porque reflete, como afirmara Baremblitt (1994), que o processo de institucionalização, assentando-se nos valores sociais, classifica e divide a realidade social. No entanto, na $6^{\text {a }}$ fase, estratégias de democratização do ensino têm sido adotadas, sinalizando a intenção de romper com o instituído, construindo outro marco institucionalizante.

A dualidade do sistema educacional referese às definições existentes desde a criação da $\mathrm{EP}$, que não a destinavam à classe dominante. Considerando que a herança escravagista "influenciou preconceituosamente as relações sociais e a visão da sociedade sobre a educação e formação profissional" (Parecer CNE/CEB n. 16/1999, p. 6) e contribuiu na institucionalização da separação entre o trabalho manual e intelectual, a EP se consolidou como educação para os desfavorecidos. Segundo os documentos, até parte da $3^{\text {a }}$ fase, a EP não permitia ao egresso a entrada no nível superior. O Decreto n. $8.673(03 / 02 / 1942)$, por exemplo, estabelecia mais disciplinas técnicas e menos científicas nos chamados cursos industriais, distinguindo a EP do ensino tradicional. Apesar da equiparação dos cursos no nível médio na $3^{\text {a }}$ fase, a dualidade se manteve, principalmente nos níveis mais elevados da educação, visto o controle social do acesso ao ensino. A lei da reforma do ensino superior (Lei n. 5.540, 28/11/1968), por exemplo, deflagrou movimentos contrários aos mecanismos altamente seletivos de entrada nas universidades, vistos como uma forma de manutenção da estrutura de desigualdade social (Azevedo et al., 1932/2006). Segundo Souza (2009), a meritocracia de um lado valoriza o talento individual e, de outro, culpabiliza os indivíduos pelo fracasso e justifica privilégios dos grupos no poder, sem ter em conta as condições de desenvolvimento dos talentos. Processo social, portanto, eminentemente dialético, em que além de haver uma dupla face, uma depende da outra.
Observou-se nos documentos que a EP teve momentos de crescimento e recuo no setor público e crescimento no setor privado com o deslocamento da fronteira da responsabilidade pela educação superior entre o setor público e o privado ao longo da história. Desde a $1^{\text {a }}$ fase, quando foi criado o Collegio das Fábricas (Decreto de 23/03/1809), havia iniciativas privadas como os Liceus de Artes e Ofícios (Parecer CNE/CEB n. 16, 1999). A $2^{\text {a }}$ fase foi marcada pela responsabilização do Estado pela EP, considerando dever do governo formar cidadãos úteis à nação, criar escolas de aprendizes e artífices e institucionalizar a rede de ensino profissionalizante, custeadas pela União ou pelos estados, municípios ou associações particulares (Decreto n. 7.566, 23/09/1909). Na década de 1940 ( $3^{a}$ fase), houve decretos-leis responsabilizando o setor privado pela criação de escolas de ensino vocacional e pré-vocacional (Parecer CNE/CEB n. 16, 1999). Assim, a EP foi considerada dever do Estado a ser cumprido com a colaboração das empresas e dos sindicatos patronais, propiciou a institucionalização do Serviço Nacional de Aprendizagem com seus diferentes direcionamentos (Parecer CNE/CP n. 29, 2002), dando seguimento na $4^{\text {a }}$ fase.

$\mathrm{Na} 5^{\text {a }}$ fase, dirimiu-se mais a responsabilidade do Estado pela educação (Art. $209^{\circ}$, Brasil, 1988). O ponto crítico foi a proibição da expansão da oferta de educação profissional federal, restringindo a construção de novas escolas técnicas à obrigatoriedade de parcerias com estados, municípios, Distrito Federal, setor privado e/ou organizações não governamentais

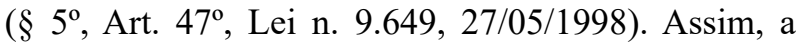
expansão ficou a cargo, principalmente, da iniciativa privada, seguindo tendência do ideário neoliberal.

A proibição foi revogada na $6^{\mathrm{a}}$ fase, a rede pública foi reorganizada, expandiram-se e ampliaramse as parcerias público-privadas pela implantação de políticas compensatórias, como o Programa Universidade para Todos (Lei n. 11.096, 13/01/2005). A expansão da rede, por um lado, cria a possibilidade de ascensão ao ensino superior e, por outro, a restringe, visto o aporte dado ao ensino privado. Segue-se a reprodução de uma sociedade de classes no sistema educacional brasileiro (Parecer CNE/CEB n. 16, 1999), com escolas para a classe dominante e escolas para o povo (Bourdieu \& Passeron, 1975); no caso do ensino superior brasileiro, rede pública e privada, respectivamente (Campello et al., 2009; Rosas, 1992).

Sobre o desenvolvimento econômico e tecnológico, os documentos evidenciaram que a EP sempre esteve ligada a seus interesses. Responde a demandas como: produzir manufaturados, antes importados ( $1^{\text {a }}$ fase); a transição para a mecanização 
agrícola ( $2^{\mathrm{a}}$ fase); industrialização ( $3^{\mathrm{a}}$ fase); técnicos e trabalhadores qualificados para a produção em série (4 fase); profissionais que acompanhem o avanço tecnológico e mantenham lucros e competitividade $\left(5^{\mathrm{a}}\right.$ e $6^{\text {a }}$ fases).

De modo geral, até a década de 1970, a educação para o trabalho "limitava-se ao treinamento para a produção em série" (Parecer CNE/CEB n. 16, 1999, p. 6; Parecer CNE/CES n. 436/01, p. 1). No entanto, nas décadas de 1980 e 1990, principalmente nesta última, a introdução da computação e pela capacidade de observação em escalas macro (cósmicas) e nano (átomos e moléculas) (Parecer CNE/CES n. 277, 2006), entre outros avanços, transformaram os métodos de trabalho. Maior concorrência e novas exigências se instalaram (Parecer CNE/CP n. 29, 2002). As transformações políticas, econômicas e sociais geraram novas necessidades, formas de organização e de gestão do trabalho, culminando na introdução do termo tecnológico quando se trata de EP e na necessidade de um nível mais elevado de escolarização (Parecer CNE/CEB n. 16, 1999). Da relação entre educação e crescimento econômico, considera-se que "o aumento de um ano na média educacional da população economicamente ativa determina um incremento de $5,5 \%$ do PIB (Produto Interno Bruto)" (Lei n. 10.172, 09/01/2001), por exemplo.

Segundo Baremblitt (1994), instituir é definir uma realidade social e as condutas humanas em tal realidade, classificando-as, atribuindo valores e norteando decisões. Assim, as análises dos documentos normativos que se terminou por apresentar apreenderam a institucionalização da EP como um processo dialético que envolve forças fortalecedoras e enfraquecedoras. Entre as primeiras estão o aumento da atividade normativa (Tabela 2 - Ver final do artigo), a ampliação do papel do Estado na valorização desta modalidade de formação educacional no atual século e o reconhecimento crescente do papel econômico da EP. Entre as segundas forças, pode-se perceber a oscilação nos períodos históricos entre valorizar a EP ou tratá-la como algo de menor valor, destinada aos desfavorecidos. Como os processos instituintes são atravessados pelas relações de poder (Hall \& Taylor, 2003), tais oscilações provavelmente refletem a alternância de poder político no país, ainda que as ideias assistencialistas e moralistas das primeiras fases sobrevivam na sociedade.

Os cursos de GRH, como outros CSTs, devem "adotar a flexibilidade, a interdisciplinaridade, a contextualização e a atualização permanente dos cursos e seus currículos" (Resolução CNE/CP n. 03, 2002 , p. 1), considerando a graduação etapa inicial da formação continuada (Parecer CNE n. 776, 1997). Espera-se que a flexibilidade fundamente a autonomia dos EES em relação à oferta dos cursos, concepção do currículo e perfil do profissional a ser formado, aos métodos e processos de aprendizado e de avaliação e que se reflita no PPC construído com participação de todos os atores educacionais, especialmente dos docentes. A interdisciplinaridade exige integração dos conteúdos para o desenvolvimento das competências. A contextualização se refere à aplicação do aprendizado no trabalho real, integrando esses pontos à contínua atualização dos cursos e currículos e atendendo, simultaneamente, as demandas dos trabalhadores, empregadores, sociedade, regionalidades e vocação do EES (Parecer CNE/CEB n. 16, 1999; Parecer CNE/CP n. 29, 2002).

Segundo a Resolução CNE/CP n. 03/2002, as competências profissionais a serem desenvolvidas devem expressar-se nos PPCs, no perfil profissional de conclusão e em outros itens necessários para aprovação do mesmo, como justificativa e objetivo, organização do currículo e informações sobre acesso, avaliação da aprendizagem e das competências adquiridas anteriormente, instalações e equipamentos, pessoal técnico e docente.

Analisaram-se 24 PPCs de GRH de nove estados: São Paulo ( $\mathrm{f}=11$ ); Paraná $(\mathrm{f}=3$ ); Minas Gerais, Rio Grande do Sul e Rondônia ( $\mathrm{f}=2$, cada); Mato Grosso, Mato Grosso do Sul, Rio Grande do Norte e Sergipe ( $\mathrm{f}=1$, cada). São vinculados às faculdades $(\mathrm{f}=11)$, centros universitários $(\mathrm{f}=7)$, universidades $(\mathrm{f}=5)$ e instituto federal $(\mathrm{f}=1)$ e apresentam categoria administrativa privada com fins lucrativos ( $\mathrm{f}=13$ ), privada sem fins lucrativos $(\mathrm{f}=10)$ e pública federal $(\mathrm{f}=1)$.

Dos PPCs analisados, apenas quatro fundamentaram-se em pesquisas sobre o perfil profissional do tecnólogo de GRH. Um mencionou um aumento de $19 \%$ para $36 \%$ na empregabilidade para portadores de diploma superior, com aumento de quatro mil postos de trabalho de 2005-2007 e carência de profissionais qualificados no Sistema Nacional de Emprego sem identificar a fonte dessas informações. Um segundo mencionou pesquisas, realizadas por alunos como parte obrigatória da formação, sobre o mercado de trabalho para o profissional de Recursos Humanos.

Um terceiro relatou pesquisas que apontavam que, embora existam atividades de GRH como recrutamento e seleção, treinamentos e programas de melhoria da saúde em empresas da região, essas são realizadas, na maioria das vezes, por outros profissionais. Compete questionar, então, a 
viabilidade da construção de um perfil profissional, visto que essas atividades fazem parte da atuação de profissionais de cursos tradicionais, como Psicologia e Administração. A legislação que versa sobre a criação dos cursos tecnológicos procura resguardar as atuações exclusivas das profissões reconhecidas e definir seu caráter diferenciado (Parecer $\mathrm{CNE} /$ CP n. 6, 2006). Os pontos de interseção fomentam a discussão sobre sobreposição de funções com cursos tradicionais. Compreende-se aqui que dúvidas como essas enfraquecem a legitimação social ao profissional formado em GRH. Em outras palavras, as ambiguidades no nível normativo e institucional problematizam a construção de uma identidade profissional, pois põem dúvidas sobre quem são coletivamente os tecnólogos de GRH. Sem uma identidade coletiva forte, como se constituírem como atores sociais no mundo do trabalho atual? O que não está resolvido no nível societal, representa-se neste PPC.
Finalmente, o quarto projeto justificou a implantação do curso e currículo proposto, com pesquisas junto a empresas na região, levantando demanda pelo profissional de GRH, a necessidade do conhecimento de rotinas trabalhistas e capacidade de negociação e comunicação para sua formação. Mencionou também uma pesquisa sobre o interesse de alunos do ensino médio e existência de uma parceria com a Prefeitura. Tal projeto demonstra a exequibilidade de pesquisas para identificação de demanda, exigência dos órgãos de regulação do ensino no país. Esse PPC é do único EES público.

Os demais 20 PPCs (Figura 1) ancoram suas justificativas na inserção regional $(70,8 \%)$, no crescimento econômico $(66,7, \%)$ e no discurso sobre as mudanças no mundo do trabalho $(66,7 \%)$. A inserção regional se expressa em referências a aspectos como o tamanho populacional, renda per capita, PIB e caracterização dos setores mais importantes na região.

\section{Figura 1. Justificativas e demandas por cursos de GRH nos PPCs}

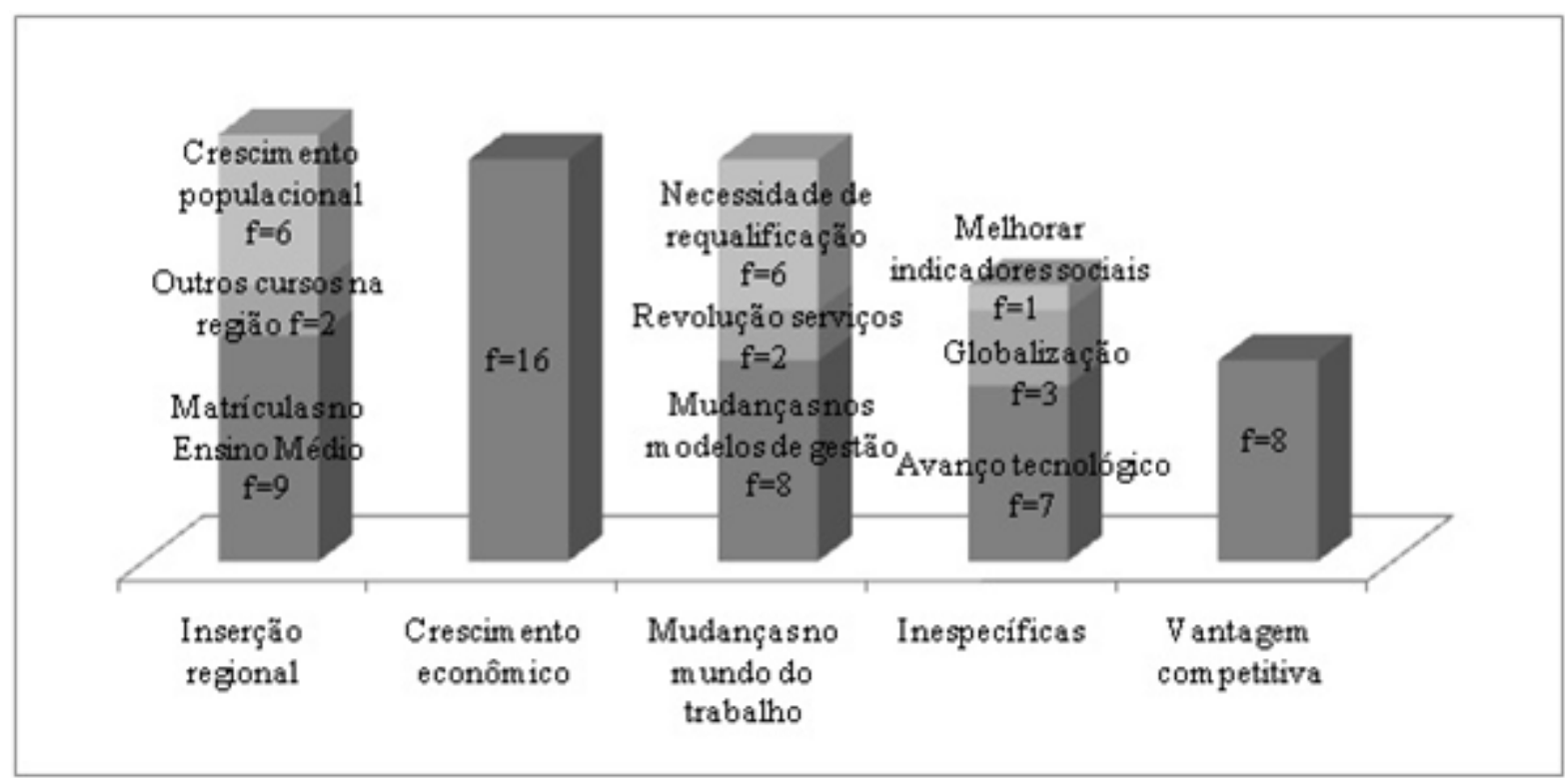

É a única justificativa para implantação do curso de GRH em dois projetos.

As mudanças no mundo do trabalho atingem a gestão, a requalificação e a revolução dos serviços. $\mathrm{O}$ argumento do crescimento econômico recorre à expansão e predominância de setores produtivos na região, bem como inclui menções a crescimento abstrato a advir, por exemplo, de investimentos do Programa de Aceleração do Crescimento à futura abertura ao Oceano Pacífico. Com exceção da menção à vantagem competitiva advinda da contratação de um profissional de GRH, as demais justificativas serviriam a qualquer CSTs, permitindo propor a hipótese de que as demandas são forjadas pelas escolas apoiadas em políticas públicas. Há, portanto, dificuldades de adequação dos cursos às necessidades de mercado, corroborando os resultados da pesquisa de Duch e Laudares (2009).

A diversidade de PPCs não se traduz em uma diferenciação nos objetivos dos cursos, bem como do perfil profissional de conclusão. Aproximam-se à definição do MEC no Catálogo de CSTs (MEC, 2010), que prescreve características vinculadas à formação geral do trabalhador, com forte base humanística, 
científica e tecnológica, incluindo competências para a tomada de decisão, atuação em equipe e adequação às mudanças do mundo do trabalho. Os PPCs não atenderam, em sua maioria, aos critérios estabelecidos para planejamento e organização de CSTs em relação à identificação de demandas dos cidadãos, do mercado de trabalho e da sociedade e aos perfis profissionais. Estão aquém do requerido pela Resolução CNE/CP n. 03/2002, permitindo o questionamento relativo à sua legitimação.

A importância do perfil profissional e a carência de pesquisas sobre as demandas regionais, indicadas na análise dos PPCs, fomenta a hipótese de que são tratados como documentos inócuos e burocráticos. A falta de padrões para apresentação dos PPCs impossibilitou identificar aspectos como o tempo de experiência profissional dos docentes. No entanto, as informações contidas permitiram identificar uma diversidade de titulações, o número de professores e formação. De 178 docentes $(87,3 \%$ do total) em 14 PPCs, $1,1 \%$ apresentam graduação, $34,2 \%$, especialização, $45,5 \%$, mestrado e $19,2 \%$, doutorado.
Esses resultados demonstraram que os EES participantes cumprem proporção requerida (Art. $52^{\circ}$, Lei n. 9.394, 20/12/1996) de ao menos $1 / 3$ do corpo docente com mestres e doutores, para universidades. Assemelham-se, também, ao perfil de docentes dos EES privados em exercício, que têm $0,56 \%$ graduados ou menos, 34,12\% especialistas, $47,09 \%$ mestres, $18,23 \%$ doutores (INEP, 2013). No entanto, quando comparados aos perfis da rede pública em que se observam 5,04\% graduados, $12,17 \%$ especialistas, 29,62\% mestres, 53,17\% doutores (INEP, 2013), evidencia-se que a rede particular está aquém da pública. Corrobora, portanto, a preocupação com a formação dos docentes e com a qualidade do ensino (Costa, 2012).

Nos 16 PPCs $(66,7 \%)$ com informações do corpo docente, identificaram-se 204 docentes, variando de 7 a 19 docentes por curso (média $=12,75, \mathrm{DP}=3,32$ ). Oito PPCs (Figura 2) registraram a formação de 111 docentes $(54,4 \%$ do total $)$, abrangendo 26 graduações distintas, sendo que há cinco docentes com duas graduações e dois, com três. Os blocos

\section{Figura 2. Distribuição dos docentes de cursos de GRH por formação acadêmica}

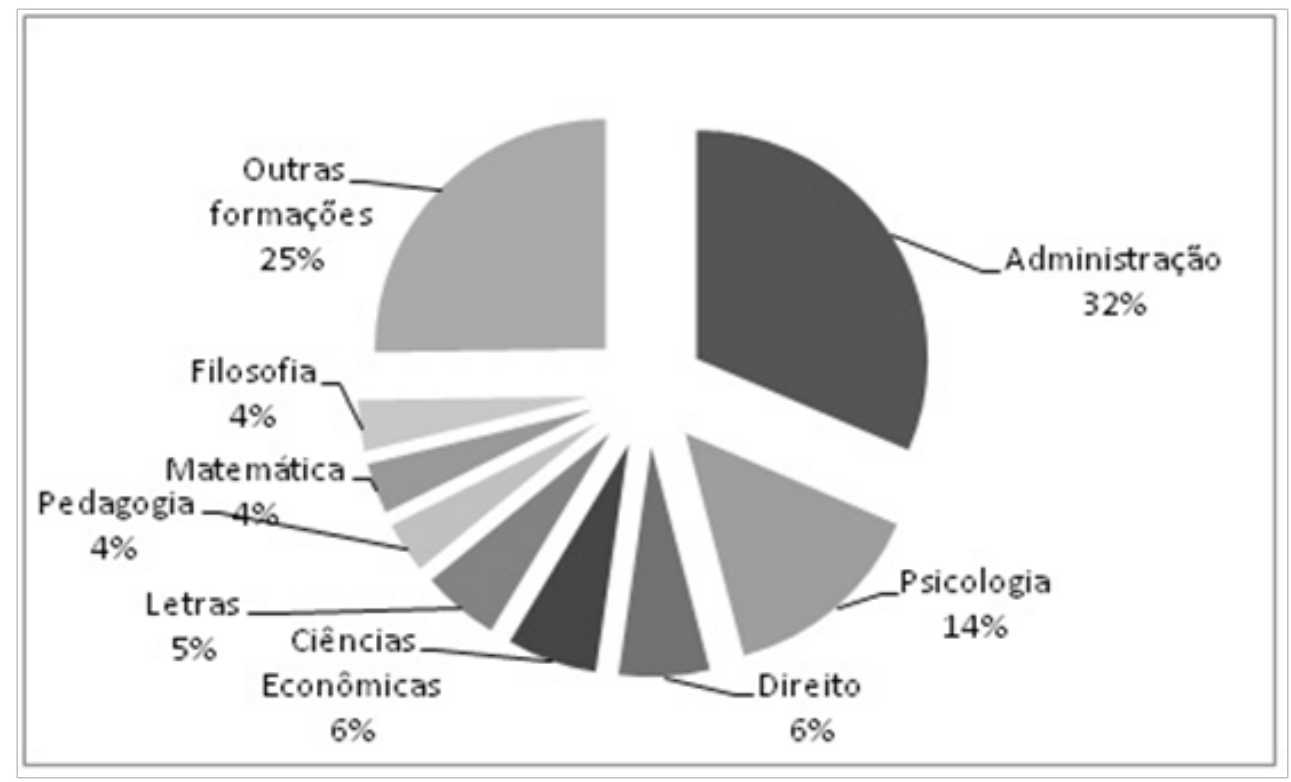

mais numerosos são as graduações em Administração e Psicologia.

Dentre as "outras formações" incluídas na Figura 2, estão as que ocorreram de uma a três vezes (e. g., Fisioterapia e História). Apenas três docentes com formação tecnológica (Gestão Educativa e Sociocultural, Empresarial e de Telecomunicações, sendo este último, também, bacharel em Engenharia Elétrica), e nenhum com formação em GRH. A variedade de formações contrapõe-se à pouca variedade de perfis profissionais prescritos nos PPCs.

Ainda que desejável certa variabilidade, por conta da natureza multidisciplinar do curso, essa grande diversidade pode expressar a indiferença dos dirigentes dos EES aos docentes e aos cursos de GRH. Em outras palavras, a desvalorização dos tecnólogos provavelmente atinge também os docentes que atuam nesses cursos. Assim, mais que uma política 
de formação de professores (Costa, 2012), é preciso questionar o que fundamenta o surgimento de cursos de GRH: se de um profissional inovador, voltado à prática e ao enfrentamento de novas questões munido de uma formação multidisciplinares, ou de um profissional de segunda classe que, com curso mais barato e rápido, serve ao mercado de ensino superior e ao mercado imediato. Dessa forma, compreendese que as forças instituintes (e desinstituintes) que já se havia apreendido na história da EP por meio dos documentos normativos mais gerais se reproduzem nos PPCs dos cursos de GRH, documento normativo mais específico. A valorização construída sóciohistoricamente estimula a criação dos cursos, mas não é suficientemente forte para garantir PPCs fundamentados como as legislações em vigor fazem esperar, nem para o setor privado investir e definir com clareza o perfil docente.

\section{Considerações finais}

Os marcos institucionais identificados na história dos CSTs, incluindo os de GRH, se refletem nos PPCs que regulam nos EES a criação, funcionamento, manutenção, financiamentos, qualidade de sua justificativa e perfil docente. $\mathrm{O}$ assistencialismo e o moralismo foram processos instituídos no início da EP no país e têm sofrido questionamentos ao longo da história em relação à função da EP dentro do sistema educacional (forças instituintes). A dualidade do sistema educacional segue a mesma linha, com questionamentos da aparente determinação dos atores sociais a quem a EP se dedica. A responsabilização do setor privado e a demanda política e social por redirecionamento para maior participação do Estado tiveram fases distintas de avanços e recuos. Provavelmente, esses movimentos refletem a alternância de influência social de segmentos políticos distintos da sociedade brasileira (atravessamentos de poder). As informações consideradas indicam que o vínculo com o desenvolvimento econômico e tecnológico se consolidou progressivamente, sinalizando a importância do mercado nacional e mundial nas decisões educacionais do país.

A indistinção do perfil profissional de conclusão e da demanda por profissionais de GRH, observados na análise dos PPCs, coaduna com a ideia de Peterossi (1980) de que "refere-se mais a uma projeção, talvez otimista, talvez ilusória, do que a uma realidade percebida ou por se fazer" (p. 60). Aparentemente, há uma contradição entre educação orientada pelos valores do mercado de trabalho e voltada para uma democracia social e econômica (Ferreti, Silva, \& Oliveira, 1999).
Essa contradição, além da desqualificação da função pública em detrimento da privada, se intensifica no intuito de servir ao mercado de ensino superior em evidente crescimento em nossa sociedade, apoiado em políticas públicas e preservando uma ideologia que mantém a classe dominante no poder.

A fundamentação dos cursos de GRH presentes nos PPCs, apoiada principalmente em aspectos gerais, parece insuficiente para justificar o número crescente de cursos de GRH no país, de 588 (556 presenciais) em 2013 para 4604 (1128 presenciais) em 2015 (http://emec.mec.gov.br). Além disso, como prática ainda em institucionalização, deve-se questionar a existência de um limite de absorção para os 39.708 concluintes dos cursos de GRH (INEP, 2013) e os significados e consequências do aumento de 10862,5\% no número de cursos a distância em apenas dois anos, o que está relacionado à manutenção, crescimento ou encolhimento dos postos de trabalho dos docentes atuantes nesses cursos.

A identificação da menor titulação docente na rede privada permite a discussão sobre a qualidade do ensino e a existência de apoio à formação, entre outros problemas que atingem os docentes. A diversidade de formações pode sinalizar a indiferença dos dirigentes dos EES aos docentes e aos cursos de GRH. As carências de objetivo e de perfil profissional bem definido, bem como a indistinção na formação do docente, aproximam-se da massificação característica do modelo econômico capitalista.

Por conta da extensão temporal e da quantidade e natureza de documentos e informações abarcadas pelas análises, apesar do rigor das buscas, certamente outros marcos institucionais poderão ser identificados. Além disso, a extensão histórica influenciou a proposição de fases extensas. Considera-se, também, que a construção do conhecimento em uma vertente institucional tem um caráter sempre lacunar (Baremblitt, 1994).

Ainda que tenha se buscado uma contextualização sócio-histórica do processo e investigação da dinâmica social, a presente pesquisa tem um caráter introdutório, abrindo espaço para o acesso à subjetividade, aos significados e às experiências, complementando a amplitude de análise requerida na perspectiva psicossociológica. $\mathrm{O}$ incremento nas pesquisas sobre os cursos de GRH precisa contribuir para a discussão do papel político, econômico e social dos CSTs no país e para orientação dos atores envolvidos. Como uma agenda de pesquisa para a PTO relacionada aos docentes atuantes em cursos de GRH, sugere-se: (a) aprofundar nas questões sobre o perfil e a necessidade 
de formação diferenciada para docentes que atuam nos CSTs, especificamente o de GRH; (b) analisar os significados atribuídos ao trabalho, à identidade docente $\mathrm{e}$ às especificidades de socialização ocupacional e ou profissional, frente à pouca valorização social do tecnólogo ; (c) explorar as estratégias de aprendizagem de suas funções diante das limitações de formação e valorização docente; (d) investigar as condições de trabalho do docente que atua nos CSTs (a existência de incentivos à formação, diferenciação salarial etc.); (e) explorar aspectos relacionados à gestão de pessoas como rotatividade, absenteísmo, satisfação no trabalho e, entre outros, interesses do campo da PTO; (f) analisar a identidade de fronteira entre os cursos de GRH e de Psicologia, como seus currículos, conteúdos teóricos, produção, etc.; (g) cotejar a experiência docente em cursos de GRH às experiências no ensino em cursos semelhantes no exterior; e (h) explorar o domínio e identificação dos docentes com os preceitos dos PPCs. Compreendemos que os docentes dos cursos de GRH têm um papel instituinte em relação à consolidação dos cursos, bem como de oferecer suporte para que os tecnólogos formados (como sujeitos ativos e atores coletivos) tenham meios para conquistarem mais valorização social para sua profissão.

\section{Referências}

Azevedo, F., Barros, R. L., Teixeira, A., _Peixoto, A., Pinto, R., Meireles, C. et al. (1932/2006). O Manifesto dos Pioneiros da Educação Nova. Revista HISTEDBR On-line (n. spe), 188-204.

Azevedo, M. L. N. (2011). O campo global da educação superior, as organizações internacionais e a hegemonia mercadorizante. In D. A. Oliveira, M. E. Pini, \& M. Feldfeber (Orgs.), Politicas educacionais e trabalho docente: perspectiva comparada (pp. 117-145). Belo Horizonte: Fino Traço.

Bayma, F. (2012). Reflexões sobre a constitucionalidade das cotas raciais em universidades públicas no Brasil: referências internacionais e os desafios pós-julgamento das cotas. Ensaio: Avaliação e Políticas Públicas em Educação, 20(75), 325-346.

Baremblitt, G. (1994). Compêndio de Análise Institucional e outras correntes. Rio de Janeiro: Rosa dos Tempos.

Bianchetti, L. (2010). O processo de Bolonha e a intensificação do trabalho na universidade: entrevista com Josep M. Blanch. Educação \& Sociedade, 31(110), 263-285.

Borges, L. O., Guimarães, L. A. M., \& Silva, S. S. (2013). Diagnóstico e promoção da saúde psíquica no trabalho. In L. O. Borges \& L. Mourão (Orgs.), O trabalho e as organizações: atuações a partir da Psicologia (pp. 581618). Porto Alegre: Artmed.

Bosi, E. (1994). Memória da Psicologia. Estudos Avançados, 8(22), 379-388.

Bourdieu, P. \& Passeron, J. C. (1975). A reprodução: elementos para uma teoria do sistema de ensino. Rio de Janeiro: Francisco Alves.
Burnier, S., Cruz, R. M. R., Durães, M. N., Paz, M. L., Silva, A. N., \& Silva, I. M. M. (2007). Histórias de vida de professores: o caso da educação profissional. Revista Brasileira de Educação, 12(35), 343-358.

Campello, A. M., Almeida, A., Costa, L., Candeias, M., Seta, M., Farah, M., \& Rangel, P. V. (2009). O ensino como negócio: a expansão da oferta dos cursos de formação de tecnólogos em saúde no Brasil. Trabalho, Educação $e$ Saúde, 7, 175-190.

Carreteiro, T. C. O. \& Barros, V. A. (2011). Clínicas do trabalho: contribuições da psicossociologia no Brasil. In P. E. Bendassolli \& L. A. P. Soboll (Orgs.), Clínicas do trabalho (pp. 208-226). São Paulo: Atlas.

Carvalho, J. M. (2007). Cidadania no Brasil. Rio de Janeiro: Civilização Brasileira.

Coelho-Lima, F. (2013). A Psicologia do Trabalho e das Organizações na formação do psicólogo no Brasil. Dissertação de Mestrado, Programa de Pós-graduação em Psicologia, Universidade Federal do Rio Grande do Norte, Natal.

Costa, M. A. (2012). Políticas de formação de professores para a educação profissional e tecnológica: cenários contemporâneos. Tese de Doutorado, Programa de Pós-graduação em Educação, Universidade Federal de Uberlândia, MG.

Duch, M. A. \& Laudares, J. B. (2009). Estudo da Implementação de Cursos Superiores de Tecnologia por Instituições de Ensino Superior Mineiras. Trabalho \& Educação, 18(2), 133-154.

Ferreti, C. I., Silva, J. R., \& Oliveira, M. R. N. (Orgs.). (1999). Trabalho, formação e currículo: para onde vai a escola? São Paulo: Xamã.

Freitag, B. (1977). Escola, estado e sociedade. São Paulo: Edart.

Godoy, A. S. (1995). Pesquisa qualitativa: tipos fundamentais. Revista de Administração de Empresas, 35(3), 20- 29.

Hall, P. A. \& Taylor, R. C. R. (2003). As três versões do neoinstitucionalismo. Lua Nova, 58, 193-223.

Instituto Nacional de Estudos e Pesquisas Educacionais Anísio Teixeira - INEP. (2013). Sinopses estatísticas da educação superior. Acesso em 14 de abril, 2015, em http://portal.inep. gov.br/superior-censosuperior-sinopse

Katzell, R. (1994). Contemporary meta-trends in industrial and organizational psychology. In H. C. Triandis, M. D. Dunnette, \& L. M. Hough (Orgs.), Handbook of Industrial \& Organizational Psychology (Vol. 4, pp. 1-94). Califórnia: Palo Alto.

Laudares, J. B. \& Tomasi, A. (2003). O técnico de escolaridade média no setor produtivo: seu novo lugar e suas competências. Educação \& Sociedade, 24(85), 1237-1256.

Minayo, M. C. S. (2006). O desafio do conhecimento: pesquisa qualitativa em saúde. Rio de Janeiro: Hucitec.

Ministério da Educação - MEC. (2010). Catálogo nacional dos cursos superiores de tecnologia. Acesso em 09 de julho, 2013, em http://portal.mec.gov.br/index.php?option=com content $\&$ view $=$ article \&id=12352\&Itemid $=719$

Munduate, L. (1997). Psicología social de la organización: las personas organizando. Madrid: Pirámide.

Parecer CNE/CP n. 29/2002, de 03 de dezembro de 2002. (2002). Diretrizes Curriculares Nacionais Gerais para a Educação Profissional de Nível Tecnológico. Brasília, DF: Autor. Acesso em 06 de março, 2013, em http://portal.mec. gov.br/cne/arquivos/pdf/cp29.pdf 
Peres, P. S. (2008). Comportamento ou instituições? A evolução histórica do neo-institucionalismo da ciência política. Revista Brasileira de Ciências Sociais, 23(68), 53-71.

Peterossi, H. G. (1980). Educação e mercado de trabalho: análise crítica dos cursos de tecnologia. São Paulo: Loyola.

Resolução CNE/CEB n. 04/99, de 08 de dezembro de 1999. (1999). Institui as Diretrizes Curriculares Nacionais para a Educação Profissional de Nível Técnico. Brasília, DF: Autor. Acesso em 28 de maio, 2013, em http://portal.mec.gov.br/ dmdocuments/rceb004 99.pdf

Resolução CNE/CP n. 03/2002, de 18 de dezembro de 2002. (2002). Institui as Diretrizes Curriculares Nacionais Gerais para a organização e o funcionamento dos cursos superiores de tecnologia. Brasília, DF: Autor. Acesso em 06 de março, 2013, em http://portal.mec.gov.br/cne/arquivos/pdf/ CP032002.pdf

Rosas, P. (1992). Para compreender a educação superior brasileira. Rio de Janeiro: Paz e Terra.

Shiroma, E. O. \& Lima, D. E. (2011). Trabalho docente na educação profissional e tecnológica e no PROEJA. Educação \& Sociedade, 32(116), 725-743.

Souza, J. (2009). A ralé brasileira: quem é e como vive. Belo Horizonte: UFMG.

Takahashi, A. R. W. \& Amorim, W. A. C. (2008). Reformulação e expansão dos cursos superiores de tecnologia no Brasil: as dificuldades da retomada da educação profissional. Ensaio: Avaliação e Políticas Públicas em Educação, 16(59), 207-228.

Therét, B. (2003). As instituições entre as estruturas e as ações. Lua Nova, 58, 225-254.

Zanelli, J. C., Bastos, A. V. B., \& Rodrigues, A. C. A. (2014). Campo profissional do psicólogo em organizações e no trabalho. In J. C. Zanelli, J. E. Borges-Andrade, \& A. V. B. Bastos (Orgs.), Psicologia, organizações e trabalho no Brasil (pp. 549-582). Porto Alegre: Artmed.

\section{Agradecimentos}

À agência de fomento Fundação de Amparo à Pesquisa do Estado de Minas Gerais (PAPG, processo 22383) e Conselho Nacional de Desenvolvimento Científico e Tecnológico (Edital Universal, processo 479219/2012-5).

Submissão em: 19/12/2014

Revisão em: 11/04/2015

Aceite em: 26/04/2015

Camila Teixeira Heleno é doutora em Psicologia pela Universidade Federal de Minas Gerais. Endereço para correspondência: Faculdade de Filosofia e Ciências Humanas/UFMG. Sala 4100. Av. Antonio Carlos, 6627. CEP 31270-901, Belo Horizonte/MG, Brasil. E-mail: camilaheleno@gmail.com

Livia de Oliveira Borges é doutora em Psicologia pela Universidade de Brasília e professora titular do Departamento de Psicologia da Universidade Federal de Minas Gerais. E-mail: liviadeoliveira@gmail.com 